C-A/AP/\#175

October 2004

\title{
AGS Main Magnets Moved and BPM Survey - Summer 2003
}

C. Spataro, L.Ahrens, M. Harvey, T. Mroczkowski, and F.X. Karl

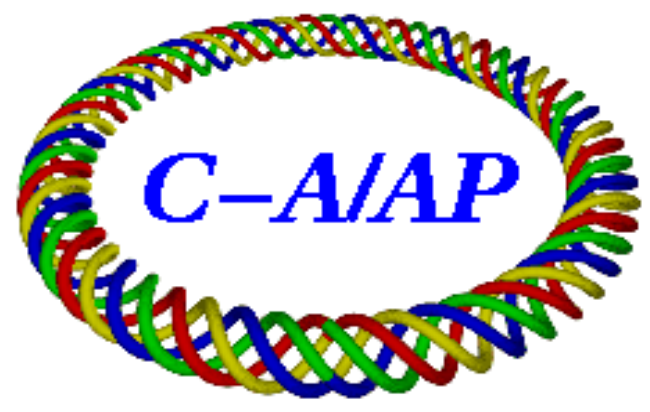

Collider-Accelerator Department Brookhaven National Laboratory Upton, NY 11973 


\title{
AGS Main Magnets Moved and BPM Survey - Summer 2003
}

\author{
C. Spataro, L. Ahrens, M. Harvey, T. Mroczkowski, and F. X. Karl
}

\section{Introduction}

During the summer of 2003 the AGS magnets were repositioned vertically and a subset horizontally, and the locations of the BPM (beam position monitor) cans were remeasured. Vertically the magnets were realigned to a "smooth" elevation curve. The horizontal adjustments involved only eight magnets, and were made to remove an intentionally added (December 1994) equilibrium orbit bump that shifted the circulating beam close to the E20 "beam catcher". The catcher was a massive beam collimator located in the E20 straight section that has since been removed from the AGS ring, replaced by th "J10 Dump". This note details these magnet moves and measurements, including the methods used - for the record. The ordering is: I. Vertical Realignment, II. Horizontal Repositioning, and III. PUE Location Resurvey.

\section{Vertical Realignment}

Using the Leica DNA03 digital level, every AGS ring dipole, from the A to L super periods, was surveyed at least three times. Using the Starnet program, a fit was done on the data and the vertical elevations of the dipoles were obtained. A projected "ideal" elevation curve for the AGS ring was produced. This curve removed any abrupt position changes but allowed low harmonic motion. The point was to reach a reasonable compromise between a machine that was vertically "perfect" - achieving which would have involved more time and risk than we could afford - and one that would not significantly distort the equilibrium orbit. Using the T-shaped leveling fixture, the AGS ring dipoles were first leveled and then elevations set to the projected ideal elevation. Every dipole was then again surveyed at least three times using the same method and a final elevation for the AGS ring dipoles was obtained from Starnet.

\section{Initial Surveying Procedure}

Using the Leica DNA03 digital level in combination with AGS control points and the two and three meter rods, scales, and a dial gauge, the elevations of the dipoles were obtained. Using the backsight-foresight-backsightforesight method, the six ring dipoles between the two control points were surveyed with the digital level. The acquired data was saved to a flash card and transferred to the Survey Group's network drive. This was done at least three times for every ring dipole.

\section{Analysis}

Using a visual basic program, the data was then extracted from the GSI format (Geo Serial Interface) into the correct format for use with the Starnet program. Using Starnet's least squares routines, the survey data is analyzed and final elevations are outputted. Finally, a table of adjustment deltas was generated between the actual elevation and the desired (projected) elevation to use as a guide for the height adjustment of the dipoles. The desired elevations were arrived at in discussions between the Survey Group and AGS accelerator physicists. After the initial survey, the magnet elevations were graphed. A desired profile was drawn on top of the graph that basically averaged out the localized peaks while maintaining a smooth gentle curve through the 
AGS that resulted in a $+/-2 \mathrm{~mm}$ deviation around $9 \theta$. A set of offsets from the actual initial data and the desired curve were calculated and used to position each dipole in the AGS ring.

\section{Leveling the Dipoles}

Starting with the A super period, the leveling T-shaped fixture was laid across the top of the dipoles, so that the three ends of the ' $T$ ' were resting on the corresponding pads on top of the dipole. Two stride levels were placed atop the leveling fixture, one along the length of the dipole to measure pitch and the other across the width of the dipole to measure the roll. The dipoles are adjusted manually in height by the use of three jacks that are not always directly under the corresponding pad on top of the dipole. A dial gauge was placed beneath the dipole as close to an outside jack as possible so that it can be read and set to zero. The pitch was adjusted first until the corresponding stride level appears level. The roll was taken out with the remaining two jacks until its' stride levels appeared level. Note that the position of the pads atop the dipoles change every magnet so that there are either one or two pads on the 'outside' (most accessible side) of the magnet.

\section{Adjusting the Dipole Elevations}

Once the dipole is deemed level, the elevation is adjusted to the desired height. Using the table of deltas for the particular dipole, the jack directly under the pad is adjusted first to the correct delta by noting the deflection in the scale that was placed beneath the dipole. A second jack is used to take out the pitch that was just introduced by the delta adjustment. Finally, the third jack is adjusted to take out the roll and make the dipole level. This was done again for every dipole in the AGS ring.

\section{Re-checking the Elevations.}

The elevations of the adjusted magnets were again taken at least three times using the Leica DNA03 digital level and then subsequently analyzed with Starnet using the same methods as the initial survey. We found some errors due to a poor setting of the scale on the dipole, etc. When this occurred the dipole was re-adjusted and a survey was done on the dipole and surrounding dipoles. Note that differences in ceiling height in the $\mathrm{G}$ super period and the few ceiling shielding blocks that were removed for maintenance purposes during the shutdown, affected the data due to air turbulence.

\section{One Crazy Magnet}

For completeness, and to explain why apparent perfection is perhaps not worth the price, mention is made of one rogue magnet whose initial coordinates were so far away from the norm that the "before" position for this magnet does not show up - is off scale - in the next graph. The H7 dipole deviated enormously from lying in the average vertical plane. The (upstream / middle / downstream) plates measured $(+.126 /-.161 /+.024)$ inches. So this magnet had a very large roll and pitch. At the end of the repositioning this magnet was aligned with its peers. How the magnet came to be so far off is not understood - but it was. Past procedures for aligning the ring have followed very much the same rules as the effort reported here.

\section{The Numbers}

The following plot (and Appendix I) give the actual numbers taken. 


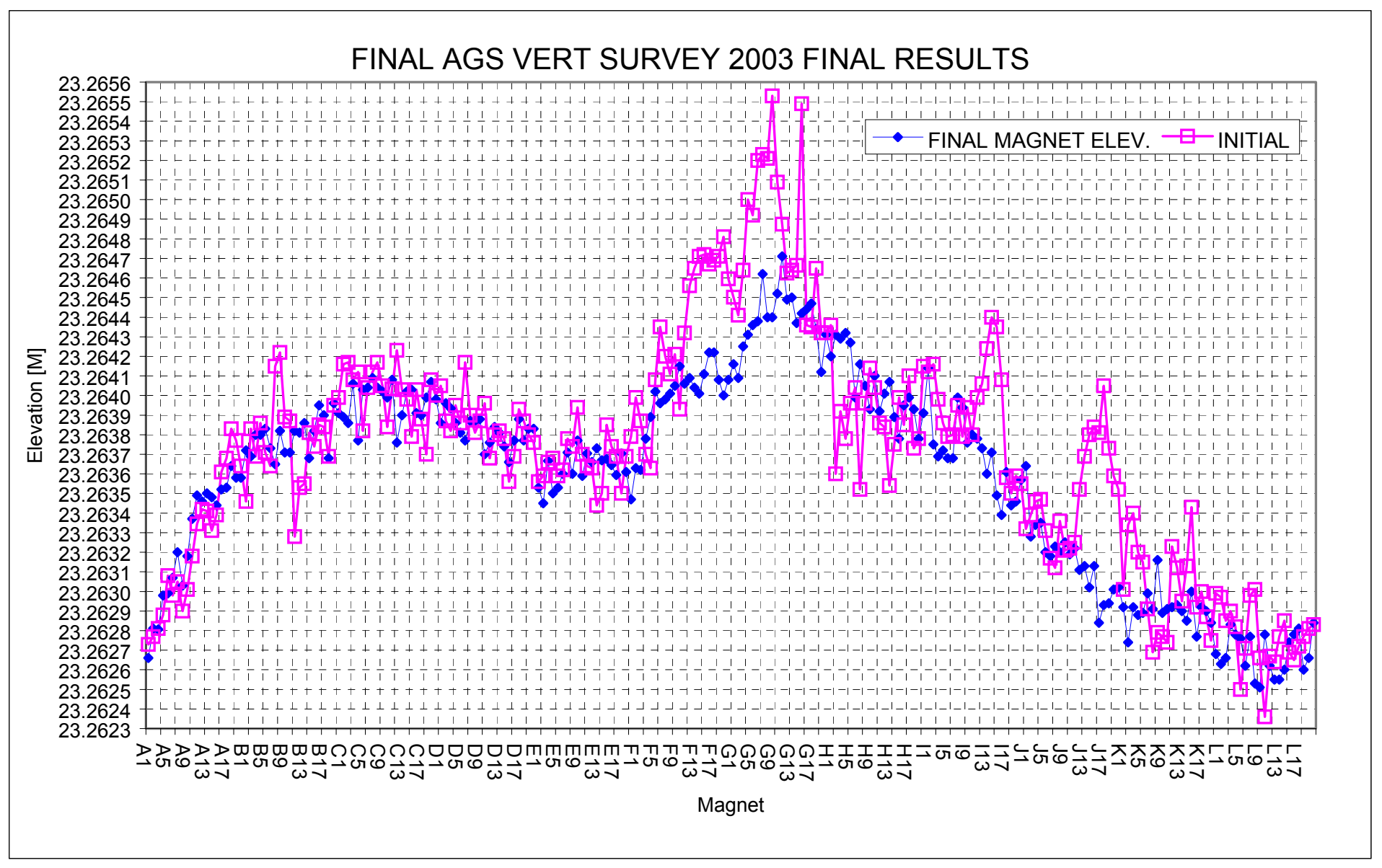

Figure 1. Through the re-iterative process of adjustments, surveying, and analysis using Starnet, the initial and final elevations of all the dipoles in the AGS were determined.

\section{Horizontal Repositioning}

The second AGS magnet repositioning during the summer of 2003 involved the horizontal positions of a handful of AGS main magnets. These had been intentionally misplaced in December of 1994 in order to bump the AGS beam (high intensity proton beam) into the then new E20 beam catcher. The moves made in 1994 had a slightly complicated history that is explained here in an attempt to reduce confusion. This follows a memo from Roy Thern to Frank Karl, dated 31Dec94.

Based on calculations of the bump amplitude required to aperture the injecting beam slightly at the catcher, eight AGS main magnets, four pairs, were shifted to create a 3/2 lambda bump with an inward max at E20. The original shifts (17 Dec 94) worked well at injection, but when slow extraction was attempted the distortion resulted in an aperture on the extracting beam. A second set of shifts, undoing half of the original ones, was then carried out (31Dec94) and the machine was left in that horizontal state until the moves of 2003 described here. 
The original move (17Dec94):

$\begin{array}{llr}\text { magnets } & \text { direction } & \text { motion (inches) } \\ \text { D19\&20 } & \text { in } & 0.136 \\ \text { E13\&14 } & \text { in } & 0.100 \\ \text { F07\&08 } & \text { out } & 0.114 \\ \text { G01\&02 } & \text { out } & 0.120\end{array}$

where "in" means movement to smaller machine radius, away from the aisle.

The additional move to undo half of this (31Dec94):

magnets direction motion (inches)

D19\&20 out $\quad 0.068$

E13\&14 out 0.050

$\mathrm{F} 07 \& 08$ in 0.057

G01\&02 in $\quad 0.060$

During the summer of 2003 then, the second step in this dance was simply repeated yet again, resulting in the main magnets being returned to their original positions - in this relative sense. That is, these moves were all done "locally", using dial gauges to measure the changes being applied. There are sextupole magnets downstream of the \#13 and \#7 main magnets. The exact history of their repositioning is not described. During the 2004 shutdown (long after all of the moves described in this note), the sextupoles are all being repositioned relative to their neighbor magnets according to the standard procedures that know nothing about these magnet moves and so their horizontal locations should be proper.

\section{PUE Position Resurvey}

The equilibrium orbit measuring system in the AGS involves detectors (PUEs = pick-up electrodes) whose locations relative to the design orbit are not strongly constrained. In many machines - e.g. the AGS Booster and in RHIC (with some noteworthy exceptions) the mechanical assembly detecting the beam position is well locked to adjacent quadrupoles. In the combined-function AGS this situation does not pertain. The positions of the PUEs are not well constrained by the geometry and so measuring the locations of the PUE cans is required. Further, with the passing of time, a revisit of these measurements is required. This business is the subject of AGS Tech notes \#183 and \#452. A review of the latest in this work is included as Appendix II. The current table of offsets is given in Appendix III. 


\section{Appendix I}

\section{Vertical Magnet Survey (meters)}

\begin{tabular}{|c|c|c|}
\hline MAGNET & INITIAL & $\begin{array}{c}\text { FINAL } \\
\text { MAGNET } \\
\text { ELEV. }\end{array}$ \\
\hline $\mathrm{A} 1$ & 23.26273 & 23.26266 \\
\hline $\mathrm{A} 2$ & 23.26277 & 23.26281 \\
\hline $\mathrm{A} 3$ & 23.26281 & 23.26281 \\
\hline A4 & 23.26288 & 23.26298 \\
\hline A5 & 23.26308 & 23.26299 \\
\hline A6 & 23.26298 & 23.26307 \\
\hline A7 & 23.26305 & 23.26320 \\
\hline $\mathrm{A} 8$ & 23.26290 & 23.26303 \\
\hline A9 & 23.26301 & 23.26318 \\
\hline A10 & 23.26318 & 23.26337 \\
\hline A11 & 23.26335 & 23.26349 \\
\hline A12 & 23.26342 & 23.26346 \\
\hline A13 & 23.26341 & 23.26350 \\
\hline A14 & 23.26331 & 23.26348 \\
\hline A15 & 23.26339 & 23.26344 \\
\hline A16 & 23.26361 & 23.26352 \\
\hline A17 & 23.26368 & 23.26353 \\
\hline A18 & 23.26383 & 23.26364 \\
\hline A19 & 23.26377 & 23.26358 \\
\hline A20 & 23.26364 & 23.26358 \\
\hline B1 & 23.26346 & 23.26372 \\
\hline B2 & 23.26383 & 23.26369 \\
\hline B3 & 23.26369 & 23.26380 \\
\hline B4 & 23.26386 & 23.26380 \\
\hline B5 & 23.26371 & 23.26383 \\
\hline B6 & 23.26364 & 23.26373 \\
\hline B7 & 23.26415 & 23.26365 \\
\hline B8 & 23.26422 & 23.26382 \\
\hline B9 & 23.26389 & 23.26371 \\
\hline B10 & 23.26387 & 23.26371 \\
\hline B11 & 23.26328 & 23.26382 \\
\hline B12 & 23.26353 & 23.26381 \\
\hline B13 & 23.26355 & 23.26386 \\
\hline B14 & 23.26381 & 23.26368 \\
\hline B15 & 23.26374 & 23.26382 \\
\hline B16 & 23.26385 & 23.26395 \\
\hline B17 & 23.26384 & 23.26390 \\
\hline B18 & 23.26369 & 23.26368 \\
\hline B19 & 23.26395 & 23.26396 \\
\hline
\end{tabular}

\begin{tabular}{|c|c|c|}
\hline MAGNET & INITIAL & $\begin{array}{l}\text { FINAL } \\
\text { MAGNET } \\
\text { ELEV. }\end{array}$ \\
\hline $\mathrm{B} 20$ & 23.26399 & 23.26391 \\
\hline $\mathrm{C} 1$ & 23.26416 & 23.26389 \\
\hline $\mathrm{C} 2$ & 23.26417 & 23.26386 \\
\hline $\mathrm{C} 3$ & 23.26408 & 23.26406 \\
\hline $\mathrm{C} 4$ & 23.26412 & 23.26377 \\
\hline $\mathrm{C} 5$ & 23.26382 & 23.26403 \\
\hline C6 & 23.26404 & 23.26404 \\
\hline $\mathrm{C} 7$ & 23.26412 & 23.26409 \\
\hline $\mathrm{C} 8$ & 23.26417 & 23.26404 \\
\hline $\mathrm{C} 9$ & 23.26405 & 23.26402 \\
\hline $\mathrm{C} 10$ & 23.26384 & 23.26399 \\
\hline $\mathrm{C} 11$ & 23.26404 & 23.26408 \\
\hline $\mathrm{C} 12$ & 23.26423 & 23.26376 \\
\hline $\mathrm{C} 13$ & 23.26403 & 23.26390 \\
\hline $\mathrm{C} 14$ & 23.26398 & 23.26402 \\
\hline $\mathrm{C} 15$ & 23.26379 & 23.26403 \\
\hline $\mathrm{C} 16$ & 23.26403 & 23.26391 \\
\hline $\mathrm{C} 17$ & 23.26388 & 23.26390 \\
\hline $\mathrm{C} 18$ & 23.26370 & 23.26399 \\
\hline $\mathrm{C} 19$ & 23.26408 & 23.26407 \\
\hline $\mathrm{C} 20$ & 23.26400 & 23.26398 \\
\hline D1 & 23.26405 & 23.26386 \\
\hline $\mathrm{D} 2$ & 23.26387 & 23.26396 \\
\hline D3 & 23.26382 & 23.26394 \\
\hline D4 & 23.26395 & 23.26386 \\
\hline D5 & 23.26386 & 23.26381 \\
\hline D6 & 23.26417 & 23.26377 \\
\hline D7 & 23.26390 & 23.26387 \\
\hline $\mathrm{D} 8$ & 23.26381 & 23.26387 \\
\hline D9 & 23.26387 & 23.26388 \\
\hline D10 & 23.26396 & 23.26370 \\
\hline D11 & 23.26368 & 23.26376 \\
\hline D12 & 23.26380 & 23.26384 \\
\hline D13 & 23.26382 & 23.26381 \\
\hline D14 & 23.26378 & 23.26374 \\
\hline D15 & 23.26356 & 23.26366 \\
\hline D16 & 23.26369 & 23.26377 \\
\hline D17 & 23.26393 & 23.26388 \\
\hline D18 & 23.26387 & 23.26377 \\
\hline
\end{tabular}




\begin{tabular}{|c|c|c|}
\hline MAGNET & INITIAL & $\begin{array}{c}\text { FINAL } \\
\text { MAGNET } \\
\text { ELEV. }\end{array}$ \\
\hline D19 & 23.26380 & 23.26383 \\
\hline D20 & 23.26376 & 23.26383 \\
\hline E1 & 23.26356 & 23.26353 \\
\hline E2 & 23.26359 & 23.26345 \\
\hline E3 & 23.26366 & 23.26367 \\
\hline E4 & 23.26368 & 23.26350 \\
\hline E5 & 23.26359 & 23.26353 \\
\hline E6 & 23.26362 & 23.26360 \\
\hline E7 & 23.26378 & 23.26371 \\
\hline E8 & 23.26374 & 23.26360 \\
\hline E9 & 23.26394 & 23.26377 \\
\hline E10 & 23.26370 & 23.26359 \\
\hline E11 & 23.26364 & 23.26371 \\
\hline E12 & 23.26363 & 23.26366 \\
\hline E13 & 23.26344 & 23.26373 \\
\hline E14 & 23.26350 & 23.26367 \\
\hline E15 & 23.26385 & 23.26368 \\
\hline E16 & 23.26374 & 23.26365 \\
\hline E17 & 23.26369 & 23.26360 \\
\hline E18 & 23.26350 & 23.26371 \\
\hline E19 & 23.26369 & 23.26361 \\
\hline E20 & 23.26379 & 23.26347 \\
\hline F1 & 23.26399 & 23.26363 \\
\hline $\mathrm{F} 2$ & 23.26387 & 23.26362 \\
\hline F3 & 23.26370 & 23.26378 \\
\hline F4 & 23.26363 & 23.26389 \\
\hline F5 & 23.26408 & 23.26402 \\
\hline F6 & 23.26435 & 23.26396 \\
\hline F7 & 23.26420 & 23.26398 \\
\hline F8 & 23.26411 & 23.26401 \\
\hline F9 & 23.26421 & 23.26405 \\
\hline F10 & 23.26393 & 23.26415 \\
\hline F11 & 23.26432 & 23.26406 \\
\hline F12 & 23.26456 & 23.26409 \\
\hline F13 & 23.26465 & 23.26404 \\
\hline F14 & 23.26471 & 23.26401 \\
\hline F15 & 23.26472 & 23.26411 \\
\hline F16 & 23.26467 & 23.26422 \\
\hline F17 & 23.26469 & 23.26422 \\
\hline F18 & 23.26471 & 23.26408 \\
\hline F19 & 23.26481 & 23.26400 \\
\hline F20 & 23.26460 & 23.26408 \\
\hline G1 & 23.26450 & 23.26416 \\
\hline $\mathrm{G} 2$ & 23.26441 & 23.26409 \\
\hline G3 & 23.26464 & 23.26425 \\
\hline
\end{tabular}

\begin{tabular}{|c|c|c|}
\hline MAGNET & INITIAL & $\begin{array}{l}\text { FINAL } \\
\text { MAGNET } \\
\text { ELEV. }\end{array}$ \\
\hline G4 & 23.26500 & 23.26431 \\
\hline G5 & 23.26492 & 23.26436 \\
\hline G6 & 23.26520 & 23.26438 \\
\hline G7 & 23.26523 & 23.26462 \\
\hline G8 & 23.26521 & 23.26440 \\
\hline G9 & 23.26553 & 23.26440 \\
\hline G10 & 23.26509 & 23.26452 \\
\hline G11 & 23.26488 & 23.26471 \\
\hline G12 & 23.26463 & 23.26449 \\
\hline G13 & 23.26464 & 23.26450 \\
\hline G14 & 23.26467 & 23.26437 \\
\hline G15 & 23.26549 & 23.26442 \\
\hline G16 & 23.26436 & 23.26444 \\
\hline G17 & 23.26435 & 23.26447 \\
\hline G18 & 23.26465 & 23.26434 \\
\hline G19 & 23.26432 & 23.26412 \\
\hline G20 & 23.26432 & 23.26431 \\
\hline $\mathrm{H} 1$ & 23.26436 & 23.26420 \\
\hline $\mathrm{H} 2$ & 23.26360 & 23.26431 \\
\hline $\mathrm{H} 3$ & 23.26392 & 23.26429 \\
\hline $\mathrm{H} 4$ & 23.26378 & 23.26432 \\
\hline $\mathrm{H} 5$ & 23.26396 & 23.26427 \\
\hline H6 & 23.26404 & 23.26399 \\
\hline $\mathrm{H} 7$ & 23.26352 & 23.26416 \\
\hline $\mathrm{H} 8$ & 23.26396 & 23.26405 \\
\hline H9 & 23.26414 & 23.26393 \\
\hline $\mathrm{H} 10$ & 23.26404 & 23.26410 \\
\hline H11 & 23.26386 & 23.26392 \\
\hline $\mathrm{H} 12$ & 23.26384 & 23.26401 \\
\hline $\mathrm{H} 13$ & 23.26354 & 23.26407 \\
\hline $\mathrm{H} 14$ & 23.26375 & 23.26389 \\
\hline $\mathrm{H} 15$ & 23.26399 & 23.26378 \\
\hline H16 & 23.26385 & 23.26395 \\
\hline $\mathrm{H} 17$ & 23.26410 & 23.26399 \\
\hline $\mathrm{H} 18$ & 23.26373 & 23.26393 \\
\hline H19 & 23.26378 & 23.26378 \\
\hline $\mathrm{H} 20$ & 23.26415 & 23.26391 \\
\hline I1 & 23.26412 & 23.26414 \\
\hline $\mathrm{I} 2$ & 23.26416 & 23.26375 \\
\hline $\mathrm{I} 3$ & 23.26398 & 23.26369 \\
\hline $\mathrm{I} 4$ & 23.26386 & 23.26372 \\
\hline I5 & 23.26379 & 23.26368 \\
\hline I6 & 23.26380 & 23.26368 \\
\hline I7 & 23.26395 & 23.26399 \\
\hline I8 & 23.26379 & 23.26394 \\
\hline
\end{tabular}




\begin{tabular}{|c|c|c|}
\hline MAGNET & INITIAL & $\begin{array}{l}\text { FINAL } \\
\text { MAGNET } \\
\text { ELEV. }\end{array}$ \\
\hline 19 & 23.26394 & 23.26376 \\
\hline $\mathrm{I} 10$ & 23.26380 & 23.26380 \\
\hline I11 & 23.26399 & 23.26378 \\
\hline $\mathrm{I} 12$ & 23.26406 & 23.26373 \\
\hline I13 & 23.26424 & 23.26360 \\
\hline $\mathrm{I} 14$ & 23.26440 & 23.26371 \\
\hline $\mathrm{I} 15$ & 23.26435 & 23.26349 \\
\hline $\mathrm{I} 16$ & 23.26408 & 23.26339 \\
\hline I17 & 23.26358 & 23.26361 \\
\hline $\mathrm{I} 18$ & 23.26350 & 23.26344 \\
\hline I19 & 23.26359 & 23.26346 \\
\hline $\mathrm{I} 20$ & 23.26355 & 23.26357 \\
\hline $\mathrm{J} 1$ & 23.26332 & 23.26364 \\
\hline $\mathrm{J} 2$ & 23.26339 & 23.26328 \\
\hline $\mathrm{J} 3$ & 23.26346 & 23.26334 \\
\hline $\mathrm{J} 4$ & 23.26347 & 23.26335 \\
\hline J5 & 23.26331 & 23.26320 \\
\hline J6 & 23.26317 & 23.26318 \\
\hline $\mathrm{J} 7$ & 23.26312 & 23.26323 \\
\hline $\mathrm{J} 8$ & 23.26336 & 23.26320 \\
\hline J9 & 23.26321 & 23.26325 \\
\hline $\mathrm{J} 10$ & 23.26322 & 23.26319 \\
\hline $\mathrm{J} 11$ & 23.26325 & 23.26322 \\
\hline $\mathrm{J} 12$ & 23.26352 & 23.26311 \\
\hline $\mathrm{J} 13$ & 23.26369 & 23.26313 \\
\hline $\mathrm{J} 14$ & 23.26380 & 23.26302 \\
\hline $\mathrm{J} 15$ & 23.26384 & 23.26313 \\
\hline $\mathrm{J} 16$ & 23.26381 & 23.26284 \\
\hline $\mathrm{J} 17$ & 23.26405 & 23.26293 \\
\hline $\mathrm{J} 18$ & 23.26373 & 23.26294 \\
\hline J19 & 23.26359 & 23.26301 \\
\hline $\mathrm{J} 20$ & 23.26352 & 23.26302 \\
\hline K1 & 23.26301 & 23.26292 \\
\hline $\mathrm{K} 2$ & 23.26334 & 23.26274 \\
\hline K3 & 23.26340 & 23.26292 \\
\hline K4 & 23.26320 & 23.26288 \\
\hline K5 & 23.26315 & 23.26289 \\
\hline K6 & 23.26291 & 23.26299 \\
\hline K7 & 23.26269 & 23.26291 \\
\hline K8 & 23.26279 & 23.26316 \\
\hline K9 & 23.26277 & 23.26289 \\
\hline K10 & 23.26274 & 23.26291 \\
\hline K11 & 23.26323 & 23.26292 \\
\hline K12 & 23.26312 & 23.26293 \\
\hline K13 & 23.26295 & 23.26290 \\
\hline
\end{tabular}

\begin{tabular}{|l|l|l|}
\hline MAGNET & INITIAL & $\begin{array}{c}\text { FINAL } \\
\text { MAGNET } \\
\text { ELEV. }\end{array}$ \\
\hline K14 & 23.26313 & 23.26285 \\
\hline K15 & 23.26343 & 23.26300 \\
\hline K16 & 23.26292 & 23.26277 \\
\hline K17 & 23.26300 & 23.26292 \\
\hline K18 & 23.26287 & 23.26290 \\
\hline K19 & 23.26275 & 23.26284 \\
\hline K20 & 23.26299 & 23.26268 \\
\hline L1 & 23.26297 & 23.26263 \\
\hline L2 & 23.26285 & 23.26266 \\
\hline L3 & 23.26290 & 23.26283 \\
\hline L4 & 23.26282 & 23.26278 \\
\hline L5 & 23.26250 & 23.26276 \\
\hline L6 & 23.26271 & 23.26262 \\
\hline L7 & 23.26298 & 23.26277 \\
\hline L8 & 23.26301 & 23.26253 \\
\hline L9 & 23.26266 & 23.26251 \\
\hline L10 & 23.26236 & 23.26278 \\
\hline L11 & 23.26267 & 23.26262 \\
\hline L12 & 23.26264 & 23.26255 \\
\hline L13 & 23.26277 & 23.26255 \\
\hline L14 & 23.26285 & 23.26260 \\
\hline L15 & 23.26269 & 23.26274 \\
\hline L16 & 23.26265 & 23.26278 \\
\hline L17 & 23.26272 & 23.26281 \\
\hline L18 & 23.26277 & 23.26260 \\
\hline L19 & 23.26281 & 23.26266 \\
\hline L20 & 23.26283 & 23.26284 \\
\hline & & \\
\hline
\end{tabular}




\section{Appendix II}

\section{AGS BPM Positions - A Continuing Saga. Leif Ahrens, Margaret Harvey Oct 2004}

This note goes through all the steps in the present spreadsheets that connect measured mechanical and electrical parameters with the final offsets entered into the database. In part this is motivated by a certain pain I experienced when I got to looking closely a few weeks ago at the active 'trod file' (the offset numbers applies to raw position measurements in the AGS Orbit Display Application Program), which clearly had a sign error - the worst thing that can happen in the dead reckoning business. To explain, the centers of the horizontal pue (pick-up electrode) cans are located "outside" of the desired beam position by about $10 \mathrm{~mm}$ - due to details of the AGS ring geometry. On the other hand, the centers of the vertical pue's are measured to tend to fall below the desired beam position by varying, of order one mm, amounts. This is explained again as associated with the positioning geometry, this time because the chambers tend to rest on the (vertically symmetric, but sloping) magnet laminations. Gravity provides the asymmetric bias. So the trod file, carrying out its job of correcting the raw position reported by the electronics for these offsets should move that raw horizontal position "out" and the raw vertical "down". A raw BPM (beam position monitor = pue pair + electronics perhaps + software) report indicating that the beam is centered, equal signals from the two plates, would require that the beam be outside and low. If one expects that '+' corresponds to 'up' and 'out', (which for the AGS orbit system it does), then the applied corrections must have opposite signs for horizontal and vertical. The painful observation mentioned above was simply that they had the same sign. A general sign change had crept into the system, apparently in early 2001, and then persisted to the present. A resurvey occurred in connection with the 2003 magnet survey/repositioning described in the attached note. We review and check things now, and an updated trod file has been added to the AGS Orbit Display application database.

The "dead reckoning" is reviewed, in the context of the database spread sheet - see also AGS T.N. \#452. The dead reckoning is broken up into three pieces labeled jig, xray, and capacitance.

First the "jig" correction: An ideal pue vacuum "can" lies concentric along the extension of the "socket line" (line connecting the socket holes = survey holes) of the upstream magnet. A mechanical construction (the Jig) references the PUE can to the "socket holes" in the magnets adjacent to the straight section. The present jig is the "new" geometry - rotated by 45 degrees around the longitudinal axis away from (hori/vert) to allow the measuring pins to actually contact the can.

Some essential but trivial details. PUEs are located in number 2,4,8,12,14, and 18 straight sections of each of the twelve AGS superperiods. The pin-positioning micrometers read .500 (inches - inches everywhere till we finally convert to $\mathrm{mm}$. at the end) for a perfectly positioned PUE can (in a number 4 or 14 straight section). On the spreadsheet, Mic "in" is the reading taken on the catwalk side of the beam; mic "out" is the reading from the micrometer located on the aisle side. The micrometer pins move down at $45 \%$ from the vertical as they are wound in. The number reported by the micrometer decreases as the micrometer is wound in. 
The first spreadsheet manipulation is to subtract the .500 . The results are listed as $X^{\prime}$ and $\mathrm{Y}^{\prime}$ in the spreadsheet, where $\mathrm{X}^{\prime}$ is the report from the micrometer on the aisle side. (Note there is a column reversal in- $>y^{\prime}$, out- $>x^{\prime}$ to achieve this). Historically the small motion of the vacuum chamber being measured by the survey pin before it would free wheel was added in to the horizontal measurement as a correction at this point. The chamber was not expected to move vertically. With the rotated jig geometry, this correction (which was measured to be about .005 inches) is ignored.

So at this point, equal negative numbers for $\mathrm{x}^{\prime}$ and $\mathrm{y}^{\prime}$ correspond to the vacuum chamber being physically low. $X^{\prime}$ negative and $Y^{\prime}$ positive corresponds to the vacuum chamber being physically shifted toward the center of the ring - moved inward.

Now (the next two columns) we rotate into the usual x,y coordinates. The signs are set so that positive means the can is displaced from ideal 'up' and 'out'. The jig angle is taken to be exactly 45 degrees. Higher order effects causing the offset in one plane to affect the position measured in the other are ignored. (The can diameter is 7.75 inches).

Next (see Bleser AGS Tech note \# 215 (1985) we account for the fact that because the upstream-downstream magnet geometry referenced by the jig is different at the different PUE locations, a perfectly positioned PUE will report slightly different jig readings at different straight sections. This is strictly a horizontal effect. The geometry of the ring causes a fixed jig (we change nothing about the jig itself as we move from one ring location to another) that is measuring perfectly located PUE cans (in all cases the perfect can is concentric with the extension of the socket line associated with the upstream magnet), to nevertheless see one offset at straight sections (\#2 and \#12), a different offset for (\#4 and \#14) and yet another offset for (\#8 and \#18). By construction the jig reports 0.500 from both micrometers for a perfectly positioned PUE can at a \#4 (or \#14) straight section. After the 0.500 subtraction mentioned above, and rotation to usual $\mathrm{x}-\mathrm{y}$ coordinates, the perfect can reports 0.000 both $\mathrm{x}$ and $\mathrm{y}$ for $\# 4$ or \#14. The situation is necessarily different then for (\#2 and \#12) and different again for (\#8 and \#18). We need to get the magnitudes and the signs right. The answer from the old note was that a perfect can will report $+.033 "$ in a $\# 8$ or \#18, and -.066" in a \#2 or \#12. Revisiting this offset for the new jig, the relevant offsets are about $+.024 "$ for \#8 and -.057" for \#2. These false offsets need to be subtracted from the raw numbers. (Another error in the old analysis discovered during this pass was that the correction described here was applies to both of the measured (i.e. primed) coordinates instead of being applied to the horizontal after rotating. So both planes were slightly corrupted)

We agonize on the sign question. The final spreadsheet jig numbers give the can position, positive is up and out, of the can center relative to a perfect situation. A beam centered in a high can will cause the electronics to report 0.000 and so needs to have its electronic position increased - by the amount the can is high. By the same argument, a beam centered in a can which itself is shifted to the outside by some amount needs to have its electronic position increased by that amount. The jig final numbers should be added to the raw position determination. 
Moving to the capacitance sheet: what is measured is the capacitance at the vacuum feed through, (historically called the "stupakoff" - I think the word referred to a particular manufacturer of feed throughs), for the channels labeled in the ring as 1,2,3,4. The rules to turn these into up, down, in and out are given in the spreadsheet. The pue geometry gets rotated by 180 degrees going from the first half of a superperiod to the second half. The spreadsheet rule: $(1,2,3,4)$ correspond to (bottom, top, out, in) for 02, 04, and 08; and then (top, bottom, in, out) for 12, 14 and 18. For a given pair of signals (i.e. "out" and "in") the quantity difference over sum: (out-in)/(out+in) is calculated. For equal capacitors this gives zero. If the outer capacitor is larger than the inner, a centered beam - equal charge on the two plates - will generate a smaller voltage on the outer than the inner and hence give a false position - to the inside - and so need a corresponding increase. The magnitude of the offset, to first order, is just the (difference over sum) times the pue geometric factor - which is about $40 \mathrm{~mm}$ for the AGS pues. The offsets as reported should then be added to the measured position to correct for the false offset. Note: an earlier electronics system for the AGS system did not normalize each pue set (i.e the four plates at $\mathrm{C4}$ ) individually but only in an average way. Because of this, a set with an average capacitance different from the ring average required a gain correction. With the new (mid 1990's) electronics, this correction is no longer appropriate and has finally been removed.

The final correction (given in the "xray" sheet) is again strictly horizontal, this time due to our ideally located pue cans being outside of the ideal orbit. A beam reporting in raw data that it is centered in a pue is infact outside - by a lot, of order ten $\mathrm{mm}$. The raw reported position needs to be increased.

And if we measure "noise" (on average zero in electronics - no beam in the machine) we expect it will show up (after our correction) as being outside. Since the pues tend to be physically low, by the same reasoning we expect a noise signal will typically be reported as low, though this is a less significant effect than the horizontal.

We have added a "final" sign change to both horizontal and vertical, due to the way the AGS Orbit Display Application Program deals with these numbers. The program actually subtracts the Trod offsets from the measured position. 


\section{Appendix III.}

\begin{tabular}{|c|c|c|c|c|c|c|c|}
\hline pue & $\begin{array}{l}\text { jig } \\
\text { vert } \\
\text { mm }\end{array}$ & $\begin{array}{l}\text { cap } \\
\text { vert }\end{array}$ & $\begin{array}{l}\text { net vert } \\
\text { offset } \\
\mathrm{mm}\end{array}$ & $\begin{array}{l}\text { jig } \\
\text { hori } \\
\mathrm{mm}\end{array}$ & $\begin{array}{l}\text { cap } \\
\text { hori } \\
\mathrm{mm}\end{array}$ & xray & $\begin{array}{l}\text { net hori } \\
\text { offset } \\
\mathrm{mm}\end{array}$ \\
\hline & & & (invrt sign) & & & & [invrt sign] \\
\hline a2 & -7.69 & 0.89 & 6.79 & 4.30 & 0.67 & 10.68 & -15.65 \\
\hline a4 & -1.64 & 0.88 & 0.76 & 0.03 & 0.63 & 10.15 & -10.80 \\
\hline a8 & -1.91 & 0.85 & 1.07 & -4.75 & -0.13 & 10.15 & -5.26 \\
\hline a12 & -0.95 & 1.83 & -0.87 & -0.65 & 0.75 & 7.78 & -7.88 \\
\hline a14 & -2.37 & -0.55 & 2.92 & 0.07 & -0.76 & 10.15 & -9.46 \\
\hline a18 & -0.95 & -0.79 & 1.74 & -2.60 & -0.44 & 10.15 & -7.10 \\
\hline b2 & -1.71 & 0.51 & 1.20 & -1.52 & -0.44 & 7.78 & -5.82 \\
\hline b4 & -3.31 & -1.93 & 5.25 & 7.52 & 2.23 & 10.15 & -19.89 \\
\hline b8 & -2.16 & 0.39 & 1.77 & -1.48 & 0.10 & 10.15 & -8.76 \\
\hline b12 & 1.13 & 1.08 & -2.22 & -0.80 & 0.14 & 7.78 & -7.12 \\
\hline b14 & -2.05 & 0.85 & 1.20 & -7.79 & -0.68 & 10.15 & -1.67 \\
\hline b18 & -2.49 & -0.02 & 2.51 & 0.31 & 0.08 & 10.15 & -10.53 \\
\hline c2 & -0.61 & -0.86 & 1.47 & 0.84 & 0.69 & 7.78 & -9.31 \\
\hline c4 & -1.33 & -1.38 & 2.72 & 0.40 & 0.84 & 10.15 & -11.39 \\
\hline c8 & -2.71 & -0.26 & 2.97 & -2.17 & -0.66 & 10.15 & -7.32 \\
\hline c12 & 0.22 & 0.15 & -0.37 & 0.34 & -0.93 & 7.78 & -7.19 \\
\hline c14 & -2.65 & -0.06 & 2.71 & -1.61 & 0.61 & 10.15 & -9.15 \\
\hline c18 & -2.33 & -0.47 & 2.79 & -1.53 & 0.02 & 10.15 & -8.64 \\
\hline d2 & -3.25 & -0.46 & 3.71 & 0.62 & 0.40 & 7.78 & -8.80 \\
\hline d4 & -1.83 & 0.96 & 0.87 & 1.11 & 0.57 & 10.15 & -11.83 \\
\hline d8 & -1.22 & 0.11 & 1.11 & -1.26 & 0.00 & 10.15 & -8.88 \\
\hline d12 & -1.40 & -0.02 & 1.42 & 1.70 & -0.80 & 7.78 & -8.68 \\
\hline d14 & -1.92 & -0.04 & 1.97 & -1.96 & 0.51 & 10.15 & -8.70 \\
\hline d18 & -1.18 & 0.44 & 0.74 & -1.07 & -0.31 & 10.15 & -8.76 \\
\hline e2 & -2.78 & -0.32 & 3.10 & -1.52 & 0.06 & 7.78 & -6.32 \\
\hline e4 & -3.30 & 0.33 & 2.96 & 1.09 & 0.77 & 10.15 & -12.01 \\
\hline e8 & 0.00 & 0.82 & -0.82 & -0.61 & 0.67 & 10.15 & -10.21 \\
\hline e12 & -0.83 & -0.11 & 0.93 & 0.91 & -0.15 & 7.78 & -8.54 \\
\hline e14 & -2.52 & -0.46 & 2.98 & -2.58 & -0.88 & 10.15 & -6.68 \\
\hline e18 & -2.32 & 0.04 & 2.27 & -0.66 & 0.49 & 10.15 & -9.98 \\
\hline f2 & -0.55 & 0.61 & -0.06 & -0.05 & 0.67 & 7.78 & -8.41 \\
\hline $\mathrm{f} 4$ & -1.50 & 0.33 & 1.18 & -1.15 & -0.82 & 10.15 & -8.17 \\
\hline f8 & -10.83 & 0.00 & 10.83 & -0.74 & 0.00 & 10.15 & -9.41 \\
\hline $\mathrm{f} 12$ & -0.42 & -0.59 & 1.01 & -1.37 & 0.05 & 7.78 & -6.46 \\
\hline
\end{tabular}




$\begin{array}{lrrrrrrr}\text { f14 } & -0.85 & 0.44 & 0.41 & -5.80 & -0.81 & 10.15 & -3.53 \\ \text { f18 } & -0.50 & 2.92 & -2.41 & -4.35 & -1.99 & 10.15 & -3.81 \\ \text { g2 } & -1.92 & -0.96 & 2.88 & -0.47 & 0.02 & 7.78 & -7.32 \\ \text { g4 } & -3.07 & -0.51 & 3.58 & 1.35 & -1.62 & 10.15 & -9.87 \\ \text { g8 } & -2.39 & -1.73 & 4.12 & -0.48 & -0.41 & 10.15 & -9.25 \\ \text { g12 } & -0.93 & 1.81 & -0.88 & 0.11 & -0.22 & 7.78 & -7.66 \\ \text { g14 } & -2.66 & 0.24 & 2.42 & -2.01 & -0.41 & 10.15 & -7.72 \\ \text { g18 } & -0.16 & 0.15 & 0.01 & -2.24 & -0.23 & 10.15 & -7.67 \\ \text { h2 } & -2.20 & 0.09 & 2.11 & -0.82 & -0.29 & 7.78 & -6.67 \\ \text { h4 } & -2.43 & 1.37 & 1.06 & 2.33 & 0.38 & 10.15 & -12.85 \\ \text { h8 } & -0.54 & 1.09 & -0.54 & 1.33 & -1.07 & 8.64 & -8.89 \\ \text { h12 } & 2.10 & 0.02 & -2.12 & 0.68 & -0.03 & 7.78 & -8.43 \\ \text { h14 } & -1.86 & -1.36 & 3.22 & -3.08 & 0.00 & 10.15 & -7.07 \\ \text { h18 } & -1.96 & 0.49 & 1.46 & -1.96 & -0.61 & 10.15 & -7.58 \\ \text { i2 } & -1.90 & -2.88 & 4.78 & -2.97 & 0.59 & 7.78 & -5.40 \\ \text { i4 } & -1.65 & 0.30 & 1.35 & -0.65 & 0.15 & 10.15 & -9.65 \\ \text { i8 } & -2.44 & 0.19 & 2.25 & -0.93 & -0.31 & 10.15 & -8.91 \\ \text { i12 } & 0.57 & -0.33 & -0.24 & -0.85 & 0.33 & 7.78 & -7.25 \\ \text { i14 } & -1.72 & -0.07 & 1.80 & 1.80 & 0.12 & 10.15 & -12.06 \\ \text { i18 } & -2.08 & 0.18 & 1.90 & -1.12 & 0.42 & 10.15 & -9.45 \\ \text { j2 } & -1.92 & 0.28 & 1.64 & 1.07 & -0.23 & 7.78 & -8.62 \\ \text { j4 } & -2.14 & 0.00 & 2.14 & 1.17 & -0.25 & 10.15 & -11.07 \\ \text { j8 } & -2.75 & 0.51 & 2.24 & -2.03 & -0.48 & 10.15 & -7.63 \\ \text { j12 } & -1.33 & -1.92 & 3.25 & 0.05 & 1.56 & 7.78 & -9.39 \\ \text { j14 } & -1.29 & 0.86 & 0.43 & -2.30 & -1.08 & 10.15 & -6.77 \\ \text { j18 } & -2.66 & 0.91 & 1.76 & -0.51 & 0.08 & 10.15 & -9.71 \\ \text { k2 } & -0.36 & -0.19 & 0.55 & 0.51 & -0.35 & 7.78 & -7.94 \\ \text { k4 } & -2.21 & -1.51 & 3.72 & 0.88 & -0.89 & 10.15 & -10.13 \\ \text { k8 } & -0.67 & -0.59 & 1.26 & -1.62 & 0.26 & 10.15 & -8.78 \\ \text { k12 } & -1.57 & 0.28 & 1.29 & 0.09 & -0.40 & 7.78 & -7.48 \\ \text { k14 } & -1.10 & 0.13 & 0.97 & -0.88 & 0.53 & 10.15 & -9.79 \\ \text { k18 } & -3.02 & 0.52 & 2.50 & 0.61 & -0.52 & 10.15 & -10.24 \\ \text { I2 } & 0.48 & -0.24 & -0.24 & 1.79 & 0.46 & 7.78 & -10.03 \\ \text { I4 } & -2.50 & 0.69 & 1.81 & -0.67 & -0.06 & 10.15 & -9.42 \\ \text { I8 } & -2.46 & 0.61 & 1.85 & -2.03 & 0.39 & 10.15 & -8.50 \\ \text { I12 } & 0.26 & -0.11 & -0.15 & -1.83 & 0.08 & 7.78 & -6.03 \\ \text { I14 } & -2.60 & -0.89 & 3.49 & -2.86 & 0.66 & 10.15 & -7.94 \\ \text { l18 } & -2.01 & -0.05 & 2.06 & -0.14 & -0.62 & 10.15 & -9.39\end{array}$

